\title{
Renewable Energy is Solution to Our Growing Needs from Energy
}

\author{
Esam Alansari \\ Department of Electrical Engineering, University of Bridgeport, Bridgeport, CT, USA
}

\begin{abstract}
The world's population has increased and they consume a lot of energy every day from nonrenewable energy such as oil, gas and coal. This consumption waste nonrenewable energy resources. According to Lewis and Nocera (2006), "Consumption of energy has increased because of population and economic growth. We need many alternative resources for nonrenewable energy to provide increasing of demand." The renewable energy can support nonrenewable energy to face people growing demand.
\end{abstract}

Keywords: Renewable, Solar, Biomass, Wind, Energy.

\section{INTRODUCTION}

One day we will not find nonrenewable energy like oil or use the optimum material for each individual function. gas for our demand? Every things around us needs energy Any material that is easy to process, inexpensive and such as houses, hospital, cars and factories. There are abundant can be used, with the aim of delivering a highmany obstacles that face energy .Some of them are efficiency solar cell. Evolving from the dye-sensitized increasing of global population and the air pollution. Some solar cells, we found that replacing the mesoporous $\mathrm{TiO} 2$ countries around the world plan to use the renewable with mesoporous $\mathrm{Al} 2 \mathrm{O}$ resulted in a significant energy to feed their demand, and they want to save the improvement in efficiency, delivering an open-circuit environment. For example, Masdar City in the United voltage of over $1.1 \mathrm{~V}$ in a device which we term a 'mesoArab Emirates, is a city has being established which super structured solar cell'. We reason that this observed depends on the renewable energy for whole demand. Also, enhancement in open-circuit voltage is due to confinement it does not have carbon into air because it never uses fossil of the photo-excited electrons within the perovskite phase, fuel. People started tapping energy from water, from thereby increasing the splitting of the quasi-Fermi levels coal, from oil, from nuclear active materials, and from for electrons and holes under illumination, which is wind. Direct energy source, solar energy, was ignored at ultimately responsible for generating the open-circuit all levels. The world powers that promoted marketing energy grew economically powerful [1]. All these are not perennially reliable sources. The renewable energy is solution for help to cover our demand from energy, produce a new energy and save the environment. It has many resources might help to save the planet. Biomass Energy is one kind of renewable resources. Biomass term refers to organic materials. Biomass energy, or bioenergy, is the conversion of biomass into useful forms of energy such as heat, electricity and liquid fuels. Biomass has several resources and it's known to be the largest renewable global energy source. The solar energy conversion efficiency of plants is low, in practice less than 1 percent. Consequently relatively large land surfaces are required to produce a substantially amount of energy. Solar thermal power systems use various techniques to focus sunlight to heat an intermediary fluid, known as heat transfer fluid that then is used to generate steam. The steam is then used in a conventional steam turbine to generate electricity. Hydropower is the largest renewable resource used for electricity. It plays an essential role in many regions of the world with more than 150 countries generating hydroelectric power.

\section{SOLAR ENERGY}

The roles and having different tolerances for purity and optoelectronic properties. The hybrid inorganic-organic solar cell concept is 'material agnostic' in that it aims to voltage. Further removal of the thermal sintering of the mesoporous Al2O layer, and better optimization of processing, has led to meso-super structured solar cells with more than $12 \%$ efficiency .In addition, $\mathrm{CH} 3$

$\mathrm{NH} 3 \mathrm{PbI} 32 \mathrm{xCl}$ can operate relatively efficiently as a thinfilm absorber in a solution-processed planar hetero junction Solar cell configuration, delivering around 5\% efficiency when no mesostructure is involved [2].

The Sun's magnetic field is the engine and energy channel underlying virtually all manifestations of solar activity. Its evolution takes place on a wide range of spatial and temporal scales, including a prominent 11-year cycle of successive polarity reversals over the entire star. This magnetic cycle in turn modulates the physical properties of the plasma flowing away from the Sun into interplanetary space, the frequency of all geo effective eruptive phenomena (such as flares and coronal mass ejections), and the solar radiative flux over the full range of the electromagnetic spectrum-from x-rays through ultraviolet, visible, and infrared light, all the way down to radio frequencies. The Sun's heartbeat is truly magnetic, and recent numerical simulations are providing new insights into its mode of operation. Parallel advances in raw computing power and ever more sophisticated numerical algorithms make it possible to produce and investigate magnetic cycles in Sun-like spheres of thermally convicting magnetized fluid. The underlying physics is in principle well understood in the form of 
magneto hydrodynamics (or MHD), being described by the classical fluid equations augmented by Maxwell's laws of electromagnetism. The challenge lies with the strong nonlinearities characterizing the interactions of fluid flows and magnetic fields, as well as the extremely wide range of spatial and temporal scales over which these interactions take place under solar interior conditions [3].

Three snapshots of a magneto hydro dynamical numerical simulation of solar convection, carried out using the multiscale flow simulation model EULAG. The left panel shows a color rendering of the radial component of the convective flow (orange to light yellow, up flows; red to dark blue, down flows) in the subsurface layers of the simulation. The center panel shows the radial magnetic field (gray to yellow, outward-directed magnetic field; gray to green, inward-directed) at the same depth. Note how the characteristic spatial scales are the same for both quantities, which also evolve on the same temporal scale of days. The right panel shows the magnitude of the zonal magnetic field component, deep in the interior of the simulation, at the base of the convection layer. Note the banded structure at mid-latitudes, roughly symmetric about the rotation axis. This torus-like structure, and its opposite-polarity counterpart in the other hemisphere, undergoes synchronous polarity reversals on a cadence of about 40 year figure 1 .

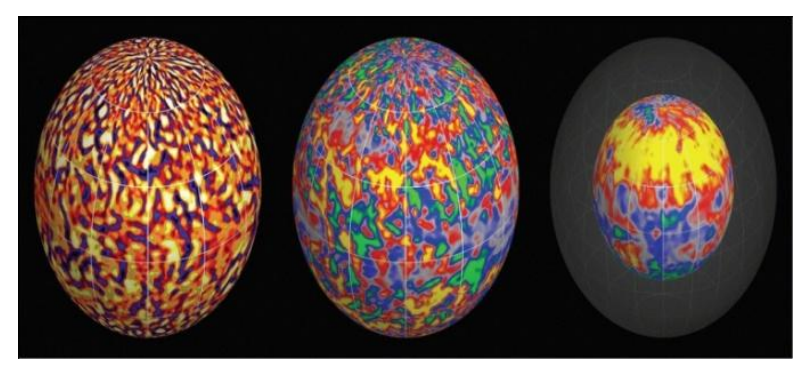

Solar simulations

\section{BIOMASS ENERGY}

Renewable energy sources currently supply somewhere between 15 percent and 20 percent of world's total energy demand. The supply is dominated by traditional biomass, mostly fuel wood used for cooking and heating, especially in developing countries in Africa, Asia and Latin America. A major contribution is also obtained from the use of large hydropower; with nearly 20 percent of the global electricity supply being provided by this source. New renewable energy sources (solar energy, wind energy, modern bio-energy, geothermal energy, and small hydropower) are currently contributing about two percent [5].

Biomass for bioenergy comes either directly from the land, as dedicated energy crops, or from residues generated in the processing of crops for food or other products such as pulp and paper from the wood industry. Another important contribution is from post-consumer residue streams such as construction and demolition wood, pallets used in transportation, and the clean fraction of municipal solid waste (MSW). The biomass to bioenergy system can be considered as the management of flow of solar generated materials, food, and fiber in our society. These interrelationships are shown in Figure 1, which presents the various resource types and applications, showing the flow of their harvest and residues to bioenergy applications figure 2 .

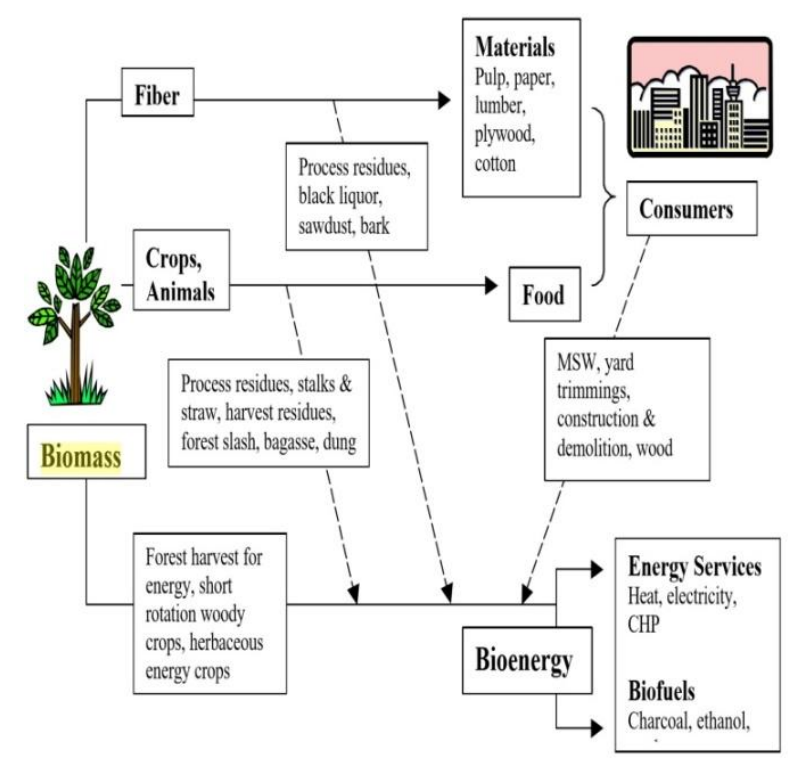

Biomass Energy

Some countries have made huge strides in this respect, notably Sweden, Austria, Brazil and China. Many others are not making the most of their resources: in Australia, for example, millions of tons of straw are still burned in fields after his harvest each year; this 'waste' could be used to generate energy. Critics often argue that the development of biofuels for transportation has caused more hunger in the world by eating up land that could be used to produce food, but there is little scientific evidence of that 4].

In fact, the development of bioenergy goes hand in hand with increased investment and higher productivity in agriculture and forestry. And because many of the byproducts are protein-rich, it could actually improve the food supply. The economic impacts of biomass energy production and consumption are generally analyzed for three socio-economic indicators: gross output, value-added and employment [6].In evaluating the economic impacts, input/output ( $\mathrm{IeO})$ models are generally used. IeO models developed multipliers that estimate the relationship between the initial effect of a change in demand and the total effects of that change. In hose models, output is the total value of production and value-added is measured as total output minus variable costs and employment, which includes the number of full- and part-time jobs in the sector [7]. Herpes [8], Gan and Smith [6], and Greener et.al. Show that models have demonstrated the multiplicative effects of bioenergy in various regions of the U.S [9].

Anaerobic digestion of biomass has been demonstrated and applied commercially with success in a multitude of situations and countries. In India biogas production from manure and wastes is applied widely in many villages and is used for cooking and power generation. Small-scale digesters have been used most extensively in India and 
China. Over 1.85 million cattle-dung digesters were installed in India by the mid-1990s, but about one-third of these are not operating for a variety of reasons, primarily insufficient dung supply and difficulties with the organization of dung deliveries. A mass popularization effort in China in the 1970s led to some 7 million household-scale digesters being installed, using pig manure and human waste as feed material. Many failed to work, however, due to insufficient or improper feed characteristics or poor construction and repair techniques

\section{WIND ENERGY}

Wind has considerable potential as a global clean energy source, being both widely available, though diffuse, and producing no pollution during power generation. Wind energy has been one of humanity's primary energy sources for transporting goods, milling grain, and pumping water for several millennia. From windmills used in China, India and Persia over 2000 years ago to the generation of electricity in the early 20th century in Europe and North America wind energy has played an important part in our recorded history. As industrialization took place in Europe and then in America, wind power generation declined, first gradually as the use of petroleum and coal, both cheaper and more reliable energy sources, became widespread, and then more sharply as power transmission lines were extended into most rural areas of industrialized countries.

In Iceland, more than $80 \%$ of the primary energy supply derives from geothermal and hydropower. Almost all electricity produced in Iceland derives from renewable sources, with $73 \%$ from hydro power plants, and $27 \%$ from geothermal plants [1]. One aspect of hydropower in Iceland is that the streamflow in rivers tends to exhibit a large annual variation, with larger flow during summer than in winter. Since the annual cycle of wind in Iceland has the opposite phase, with stronger winds in winter than in summer, wind power can potentially be used effectively in combination with hydropower. In coming decades it is expected that glacier melt will increase the hydropower potential in Iceland [2], with the increase in runoff peaking in the latter half of this century [3]. Analysis of likely changes in wind climate [4,5] does not reveal such large scale changes for the wind, and thus wind energy production may in the longer term prove to be more sustainable.

Wind energy forecasting is a challenging problem which has recently attracted increasing attention from researchers. The interested reader is referred to the survey paper [16] for a review and categorization of different approaches. In many cases, the focus is on wind speed forecasts, which are then converted to power forecasts through the power curve of the wind turbine. This is the approach taken as a reference for the comparisons of different bidding strategies in Section V. By plotting the hourly energy

Genera ted by a wind turbine versus the hourly average wind speed, it can be observed that the plotted points can be well approximated by a sigmoid function saturated below at 0 and above at. There exist several expressions for sigmoid functions [8].
A better insight into concerns and barriers to the penetration of solar and wind technologies in the domestic market was assessed through a national consultation with different stakeholders. The consultation sought to reach consensus around some key points concerning how to best gather the necessary information on resource, technology and policy and risk management requirements for expansion of the renewable energy deployment. This approach was achieved in two steps: (i) an opinion poll containing 20 assertions addressing major aspects of market regulations, government policies, education, training and technology transfer; and (ii) personal interviews seeking to clarify points raised in the first step. The opinion poll was sent to several companies, universities and research centers, governmental or nongovernmental organizations and associations, all linked directly or indirectly to solar and wind energy. Table 9 lists the content of the feedback form.

The respondent was prompted to assign a value between 0 (zero) to 5 (five) for each assertion according to its relevance from the point of view of his company or organization. The value zero (0) means the statement is irrelevant or has no importance whatsoever, and value five (5) is for the most worthy or essential assertions. Contribution to the survey was voluntary and a total of 50 out of 120 questionnaires were completed and returned in due time for analysis [7].

Since 1990 the average annual growth rate in world wind generating capacity has been 24 percent, with rates of over 30 percent in the last two years. Today there is more than $13,000 \mathrm{MW}$ of installed wind power, double the capacity that was in place just three years earlier (Figure 3). This dramatic growth rate in wind power has created one of the most rapidly expanding industries in the world, with sales of roughly $\$ 2$ billion in 1998, and predictions of tenfold growth over the next decade. Most 2000 forecasts for installed capacity are being quickly eclipsed with wind power having already passed the $10,000 \mathrm{MW}$ mark in early 1999 figure 3 .

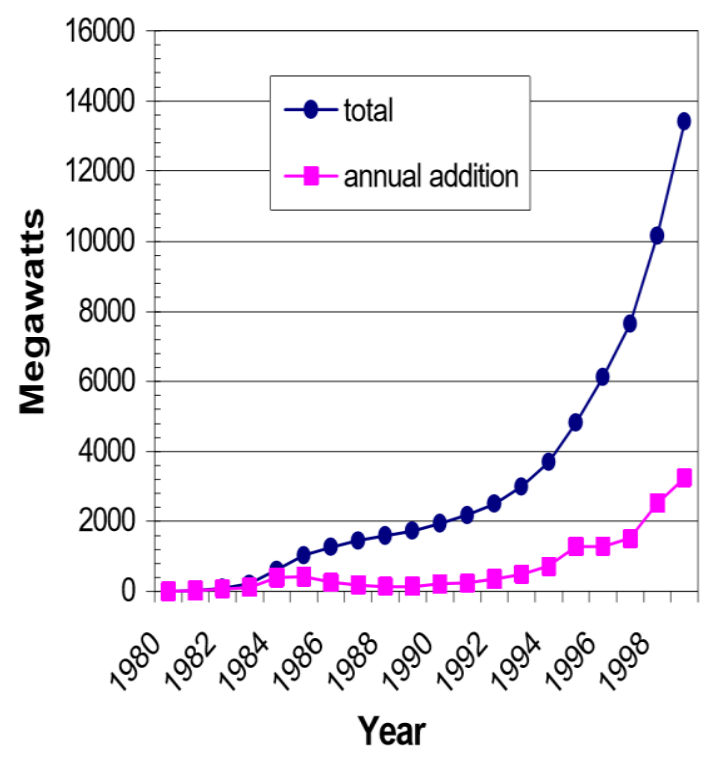

Annual growth rate in world wind generating capacity 


\section{HYDROPOWER}

Hydropower is the largest renewable resource used for electricity. It plays an essential role in many regions of the world with more than 150 countries generating hydroelectric power. A 39 survey in 1997 by The International Journal on Hydropower \& Dams found that hydro supplies at least 50 percent of national electricity production in 63 countries and at least 90 percent in 23 countries. About 10 countries obtain essentially all their commercial electricity from hydro, including Norway, several African nations, Bhutan and Paraguay.

There is about $700 \mathrm{GW}$ of hydro capacity in operation worldwide, generating $2600 \mathrm{TWh} /$ year (about 19 percent of the world's electricity production). About half of this capacity and generation is in Europe and North America with Europe the largest at 32 percent of total hydro use and North America at 23 percent of the total. However, this proportion is declining as Asia and Latin America commission large amounts of new hydro capacity.

Hydropower is a significant source of electricity worldwide and will likely continue to grow especially in the developing countries. While large dams have become much riskier investment there still remains much unexploited potential for small hydro projects around the world. It is expected that growth of hydroelectricity will continue but at a slower rate than that of the 70's and 80 's [5]. Thus, the fraction of hydroelectricity in the portfolio of primary sources of energy, which is today at 19 percent, is expected to decrease in the future. Improvements and efficiency measures are needed in dam structures, turbines, generators, substations, transmission lines, and environmental mitigation technology if hydropower's role as a clean renewable energy source is to continue to be supported. Construction of river-type hydropower plants involves uncertainties because of various external factors such as site geology, grid connection and environmental issues [4]. These factors increase the construction costs and duration. For example, in one of the river type hydropower plants, Kulp IV in Turkey, the cost of civil works increased twofold because of unpredicted geologic structure at the tunneling site. In another example, the judges have ruled against hydroelectric power plants in 33 completed cases in Turkey, issuing a stay of execution decision or canceling the construction altogether because of the environmental issues. Besides, a hydropower scheme on the Malagarasi River in Tanzania was initially approved for grant funding, but was subsequently rejected because of the identification of potentially significantly biodiversity impacts, which had not been adequately addressed in Environmental Impact Assessment (EIA) report (Hovland, 2010).

\section{CONCLUSION}

The renewable energy is alternative way to feed our requirement of energy, it create a new energy which is never depleted and preserve the environment to go green. We should work together to develop and promote the use of renewable energy because it the best way to sustain our resources for next generation and it will become the main energy in the future. Solar energy is the most effective renewable source can be used to get power. Biomass energy is a renewable energy source supply some percent of world's total energy demand. Wind has considerable potential as a global clean energy source. Hydropower is the largest renewable resource used for electricity. It plays an essential role in many regions of the world. Since 1990 the average annual growth rate in world wind generating capacity has been 24 percent, with rates of over 30 percent in the last two years. Biomass for bioenergy comes either directly from the land, as dedicated energy crops, or from residues generated in the processing of crops for food or other products.

\section{REFERNCES}

[1] Herzog, A. V., Lipman, T. E., \& Kammen, D. M. (2001). Renewable energy sources. Encyclopedia of Life Support Systems (EOLSS). Forerunner Volume-'Perspectives and Overview of Life Support Systems and Sustainable Development.

[2] Liu, M., Johnston, M. B., \& Snaith, H. J. (2013). Efficient planar Heterojunction perovskite solar cells by vapour deposition. Nature, 501(7467), 395-398.

[3] Aggidis, G.A., Luchinskaya, E., Rothschhild, R., Howard, D.C., 2010. The costs of small-scale hydropower production: impact on the development of existing potential. Renewable Energy 35, 26322638.

[4] Kahlert J, Petersen IK, Fox AD, Desholm M, Clausager I. Investigations of birds during construction and operation of Nysted offshore wind farm at Rodsand (Report Commissioned by Energi E2 A/S 2004). Denmark: National Environmental Research Institute, Ministry of the Environment; 2003

[5] Hall, D.G., Hunt, R.T., Reeves, K.S., Carroll, G.R., 2003. Estimation of Economic Parameters of US Hydropower Resources. Idaho National Engineering and Environmental Laboratory

[6] Schaffer WA. Regional impact models. Regional Research Institute, West Virginia University, 1999. In: Perez-Verdin G, Grebner DL, Munn IA, Sun C, Grado SC, editors. Economic impacts of woody biomass utilization for bioenergy in Mississippi.

[7] Rahbek A, Mosconi R. Co integration rank inference with stationary regressors in VAR models. Econometrics J 1999;2:76e91.

[8] Pesaran MH, Shin Y, Smith RJ. Bounds testing approaches to the analysis of level relationships. J App Economet 2001; 16(3): 289e326;

[9] Charbonneau, P., \& Smolarkiewicz, P. K. (2013). Modeling the solar dynamo. Science, 340(6128), 42-43. 